\title{
Prostaglandin endoperoxide synthetase isoenzymes: the clinical relevance of selective inhibition
}

Prostaglandins are mediators of inflammation, synthesised from arachidonic acid by cyclo-oxygenase. Inhibition of prostaglandin biosynthesis by blocking cyclo-oxygenase underlies the analgesic, anti-inflammatory, and antipyretic actions of the non-steroidal anti-inflammatory drugs (NSAIDs). The side effects of these drugs, including damage to the gastric wall and kidney, and inhibition of platelet aggregation, are also believed to be caused by inhibition of cyclo-oxygenase. ${ }^{1}$ Most interestingly, the action of steroids has also been explained on the basis of inhibition of prostaglandin synthesis. Most of the experiments supporting these findings were obtained in in vitro or in animal studies, but in normal volunteers acetylsalicylic acid, indomethacin, diclofenac, ibuprofen, and other NSAIDs have been shown to cause inhibition of prostaglandin synthesis, platelet thromboxane production, and renal sodium excretion.

However, the NSAIDs are not as uniform a group of drugs as these statements may suggest. For example, paracetamol is a weak anti-inflammatory drug only, and does not inhibit platelet aggregation. The suggestion was made, therefore, that paracetamol might act predominantly on a cyclo-oxygenase in the brain to produce analgesia -in effect thus predicting the existence of different forms of cyclo-oxygenase. ${ }^{2}$ A study of salicylic acid in man revealed that it had no antiaggregatory effect and, in contrast to acetylsalicylic acid, did not cause inhibition of prostaglandin synthesis in normal volunteers, in spite of equal anti-inflammatory activity. ${ }^{3}$ Furthermore, glucocorticoids, while causing inhibition of prostaglandin synthesis in in vitro studies, were ineffective in vivo. ${ }^{45}$ The authors suggested that a highly stimulated rate of prostaglandin production was in effect in the in vitro experiments, in contrast to a basal rate of production in vivo, and that this could be responsible for the different responses to the drugs. ${ }^{4}$

The discovery of two different cyclo-oxygenases, now known as COX I and COX II, has enabled the resolution of some of these discrepancies, and ushered in a new generation of NSAIDs. ${ }^{6} 7$

COX I is the constitutive enzyme serving our basic physiological functions mediated by prostaglandins. These include regulation of peripheral vascular resistance, renal blood flow, renal sodium excretion, and renin. Their inhibition can result in renal failure, sodium retention, and loss of control of hypertension. COX I also is present in blood platelets and is important for aggregation mediated by thromboxane $A_{2}$. Products of COX $I$ in the stomach wall are believed to protect the stomach from ulcers.

COX II, which shows only $60 \%$ identity of amino acid sequence with COX $I$, is induced by interleukins and mitogens (interleukin-1 (IL-1), transforming growth factor $\beta$, tumour necrosis factor $\alpha$, endotoxin and fibroblast growth factors). It, too, has an important physiological role. It is induced in pregnancy in the uteroplacental unit, and may well be the major source of enhanced prostaglandin production in pregnancy. ${ }^{8} \mathrm{COX}$ II can be induced in human monocytes, ${ }^{9}$ human synovial cells, ${ }^{10}$ and chondrocytes ${ }^{11}$ by IL-1 or endotoxin, suggesting that the enhanced prostaglandin production in inflammatory reactions is the result of COX II activation. This makes COX II an outstanding target for therapeutic interventions.

Inhibition of cyclo-oxygenase by drugs has therefore been of great interest, in particular the question which of the cyclo-oxygenase enzymes is inhibited. Biochemical investigations using cells and cell membranes in which COX I or COX II had been expressed by transfection, or in which COX II was induced by endotoxin, showed inhibition of the enzymes with indomethacin and piroxicam to be more effective against COX I, while ibuprofen and the active metabolite of nabumetone, 6-methoxy2-naphthylacetic acid (6-MNA) were more effective against COX II. ${ }^{12}$ In another study comparing the effects of indomethacin and diclofenac, diclofenac was 10 times more powerful than indomethacin as an inhibitor of COX II relative to COX I. ${ }^{13}$ Paracetamol was without effect on COX II and had only a weak effect on COX I. ${ }^{14}$ Interestingly, sodium salicylate was 20 times less effective against COX I than acetyl salicylate, but only half as effective against COX II. ${ }^{14}$ Studies on human COX I and II also showed that the two isozymes respond differently to various NSAIDs: neither was detectably affected by salicylate, COX I was the more strongly affected by indomethacin and piroxicam, and COX II was affected to a relatively greater extent by 6-MNA, ibuprofen, and diclofenac. ${ }^{15}$ While the species and the models in these studies varied considerably, the following trend emerges: indomethacin and piroxicam are particularly active on COX I while ibuprofen, diclofenac, and 6-MNA are relatively more active on COX II.

How do these data on cyclo-oxygenase inhibitory specificity of NSAIDs relate to what we know about effects of these drugs in man and in the clinical setting? Unfortunately, very few data are available on the effects of various NSAIDs in normal man and even fewer in patients. Furthermore, we know almost nothing about the expression of COX II in the various inflammatory diseases in man and the organ systems and cell types involved. While COX II is apparently a reasonable target for anti-inflammatory activity, we know nothing of the contribution of COX II products to pathophysiological processes other than inflammation. Thus, in renal disease COX II may be induced and participate in maintenance of renal function to a greater extent than the contribution of COX I generated prostaglandins. However, a few points relevant to clinical management can be made. Lack of COX I inhibitory properties would render an NSAID devoid of an effect on platelet aggregation; this is the case for paracetamol, sodium salicylate, and salsalate. Such a drug would not contribute to increased perioperative blood loss. These drugs are usually much better tolerated in acetyl salicylate sensitive asthmatics. There would be no drug interactions with diuretics, angiotensin converting enzyme inhibitors, betablockers, and lithium. Furthermore, the COX I sparing drugs would not cause acute deterioration of renal function and sodium retention in patients with renal and heart failure, as has been observed with COX I inhibitors. These aspects can be applied to advantage in the management of such patients requiring anti-inflammatory therapy. 
Cyclo-oxygenases (COX) I and II: synthesis, function and inhibition

\begin{tabular}{|c|c|c|}
\hline & $\operatorname{COX} I$ & COX II \\
\hline Enzyme synthesis & Constitutive & $\begin{array}{l}\text { Only after induction } \\
\text { (IL-1, TNF } \alpha \text {, } \\
\text { lipopolysaccharide) }\end{array}$ \\
\hline Function & $\begin{array}{l}\text { Physiological protection of } \\
\text { the stomach, regulation of } \\
\text { platelet aggregation }\left(\mathrm{TxA}_{2}\right) \text {, } \\
\text { peripheral vascular resistance } \\
\left(\mathrm{PGI}_{2}\right) \text {, renal blood flow and } \\
\text { intrarenal blood flow } \\
\text { distribution }\left(\mathrm{PGI}_{2}, \mathrm{PGE}_{2}\right) \text {, } \\
\text { sodium excretion }\left(\mathrm{PGE}_{2}\right) \text {, } \\
\text { and possibly } \mathrm{ADH} \\
\text { antagonism }\left(\mathrm{PGE}_{2}\right)\end{array}$ & $\begin{array}{l}\text { Proinflammatory } \\
\text { prostanoids }\left(\mathrm{PGE}_{2}, \mathrm{PGI}_{2}\right. \\
\left.\text { and } \mathrm{TxA}_{2}\right) \text { in fibroblasts } \\
\text { and macrophages, and } \\
\text { other cells }\end{array}$ \\
\hline $\begin{array}{l}\text { Inhibitors } \\
\text { NSAIDs }\end{array}$ & \multicolumn{2}{|c|}{ 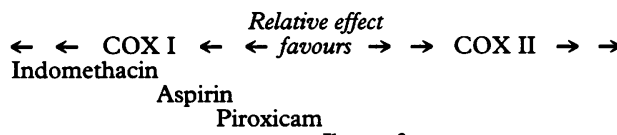 } \\
\hline & I & $\begin{array}{l}\text { ouprofen } \\
\text { Diclofenac } \\
\qquad \text { Meloxicam }\end{array}$ \\
\hline Glucocorticoids & No effect & $\begin{array}{l}\text { Inhibition of enzyme } \\
\text { synthesis }\end{array}$ \\
\hline
\end{tabular}

IL-1 = Interleukin-1; TNF $\alpha=$ tumour necrosis factor $\alpha ; \mathrm{TxA}_{2}=$ thromboxane $\mathrm{A}_{2} ; \mathrm{PG}=$ prostaglandin; $\mathrm{ADH}=$ antidiuretic hormone.

There have been large numbers of studies on gastrointestinal effects of the various NSAIDs in man. It is clear that paracetamol, nabumetone, and salsalate have very low rates of these side effects. This would be in agreement with a sparing effect of these drugs on prostaglandin synthesis (COX I) in the stomach. Sodium salicylate also is probably a very weak inhibitor of COX I in man, yet it causes gastric side effects similar to those induced by acetyl salicylate. This may be attributable to a local toxic action as salicylate is known to cause cell lysis. Indeed, even acetyl salicylate given parenterally or as an enteric coated tablet is much less of a gastric irritant than the plain tablet. Over the years, clinicians have shown a preference for diclofenac and ibuprofen, and a large meta-analysis revealed that the clinically most severe complications of NSAID therapy (upper gastrointestinal bleeding, ulcer, perforation, and death) are least with ibuprofen and much greater with indomethacin and piroxicam. ${ }^{16}$ These findings are similar to those of an analysis of major upper gastrointestinal bleeding in association with use of NSAIDs, ${ }^{17}$ and support the concept of gastric damage resulting from COX I inhibition.

Steroids would be expected to have gastrointestinal side effects similar to those of NSAIDs if they also exerted their anti-inflammatory actions by the same final pathway of inhibition of prostaglandin synthesis. This cannot be the case, as only very few patients receiving high dose glucocorticoids develop ulcers. Recently, it has been suggested that two pools of cyclo-oxygenase exist, having different sensitivities to glucocorticoids. ${ }^{9} 18$ Thus ligand stimulated eicosanoid production in monocytes, macrophages, and fibroblasts can be blocked by glucocorticoids, as a result of suppression of mRNA expression of COX II. ${ }^{19}$ Even endogenous steroid production is sufficient to restrict the production of $\mathrm{COX} \mathrm{II},{ }^{18}$ raising the possibility that the enhanced incidence of rheumatic problems in older patients is related to the decrease in endogenous glucocorticoid production.

The discovery and biochemical availability of COX I and COX II has resulted in a strong effort by the drug industry to provide new NSAIDs with selectivity for COX II. Some such selective inhibitors (for example nabumetone) may have been identified previously by serendipity during large scale screening, but now a clear biochemical objective guides the synthesis of new substances. Amongst such drugs already available in some European countries is meloxicam which, in the rat, shows 100 -fold greater selectivity for COX II than piroxicam. In clinical studies in 468 patients with rheumatoid arthritis, meloxicam was found to be an effective NSAID, yet it caused no more side effects than placebo. ${ }^{20}$

The table summarises the points outlined, and gives an indication of the relative COX I and COX II inhibitory activities of various NSAIDs.

Several drugs showing great selectivity for COX II in in vitro studies have failed in early animal or clinical trials (NS 398, CGP 28238), but many new candidates will undoubtedly be identified soon, because there is now high promise of finding an effective NSAID that is free from gastrointestinal and other side effects.

Hannover Medical School,

Institute of Clinical Pharmacology,

J C FRÖLICH

30623 Hannover, Germany

1 Vane J R. Inhibition of prostaglandin synthesis as a mechanism of action for aspirin-like drugs. Nature 1971; 231: 232-5.

2 Flower R J, Vane J R. Inhibition of prostaglandin synthetase in brain explains the anti-pyretic activity of paracetamol (4-acetamidophenol). Nature 1972; 240: 410-1.

3 Rosenkranz B, Fischer C, Meese C O, Frölich J C. Effects of salicylic and acetylsalicylic acid alone and in combination on platelet aggregation and prostanoid synthesis in man. Br f Clin Pharmacol 1986; 21: 309-17.

4 Náray-Fejes-Tóth A, Fejes-Tóth G, Fischer C, Frölich J C. Effect of dexamethasone on in vivo prostanoid production in the rabbit. $f$ Clin Invest 1984; 74: 120-3.

5 Rosenkranz B, Náray-Fejes-Tóth A, Fejes-Tóth G, Fischer C, Sawada M, Frölich J C. Dexamethasone effect on prostanoid formation in healthy man. Clin Sci 1985; 68: 681-5.

6 Xie W, Chipman J G, Robertson D L, Erikson R L, Simmons D L. Expression of a mitogen-responsive gene encoding prostaglandin synthase is regulated by mRNA splicing. Proc Natl Acad Sci USA 1991; 88: 2692-6.

7 Kujubu D A, Fletcher B S, Varnum B C, Lim R W, Herschman H R. TIS10, a phorbol ester tumor promoter-inducible mRNA from Swiss 3T3 cells, encodes a novel prostaglandin synthase/cyclooxygenase homologue. $\mathcal{F}$ Biol Chem 1991; 266: 12866-72.

8 Slater D, Berger L, Newton R, Moore G, Bennett P. The relative abundance of type 1 to type 2 cyclo-oxygenase mRNA in human amnion at term. of type 1 to type 2 cyclo-oxygenase mRNA in
Biochem Biophys Res Commun 1994; 198: 304-8.

9 Fu J-Y, Masferrer J L, Seibert K, Raz A, Needleman P. The induction and suppression of prostaglandin $\mathrm{H}_{2}$ synthase (cyclooxygenase) in human monocytes. $\mathcal{F}$ Biol Chem 1990; 265: 16737-40.

10 Angel J, Berenbaum F, Le Denmat C, Nevalainen T, Masliah J, Fournier C. Interleukin-1-induced prostaglandin $E_{2}$ biosynthesis in human synovial cells involves the activation of cytosolic phospholipase $\mathrm{A}_{2}$ and cyclooxygenase-2. Eur F Biochem 1994; 226: 125-31.

11 Knott I, Dieu M, Burton M, Houbion A, Remacle J, Raes M. Induction of cyclooxygenase by interleukin 1: Comparative study between human synovial cells and chondrocytes. $\mathcal{F}$ Rheumatol 1994; 21 : 462-6.

12 Meade E A, Smith W L, DeWitt D L. Differential inhibition of prostaglandin endoperoxide synthase (cyclooxygenase) isozymes by aspirin and other non-steroidal antiinflammatory drugs. F Biol Chem 1993; 268: $6610-4$.

13 Klein T, Nüsing R M, Pfeilschifter J, Ullrich V. Selective inhibition of cyclooxygenase 2. Biochem Pharmacol 1994; 48: 1605-10.

14 Mitchell J A, Akarasereenont P, Thiemermann C, Flower R J, Vane J R. Selectivity of nonsteroidal antiinflammatory drugs as inhibitors of constitutive and inducible cyclooxygenase. Proc Natl Acad Sci USA 1994; 90: 11693-7.

15 Laneuville O, Breuer D K, DeWitt D L, Hla T, Funk C D, Smith W L. Differential inhibition of human prostaglandin endoperoxide $H$ synthases -1 and -2 by nonsteroidal anti-inflammatory drugs. $\mathcal{F}$ Pharmacol Exp Ther 1994; 271: 927-34.

16 Gabriel S E, Jakimainen L, Bombardier C. Risk for serious gastrointestinal complications related to use of NSAID: a meta-analysis. Ann Intern Med 1991; 115: 787-96.

17 Kaufman D W, Kelly J P, Sheehan J E, et al. Nonsteroidal anti-inflammatory drug use in relation to major upper gastrointestinal bleeding. Clin Pharmacol Ther 1993; 53: 485-94.

18 Masferrer J L, Seibert K, Zweifel B, Needleman P. Endogenous glucocorticoids regulate an inducible cyclooxygenase enzyme. Proc Natl glucocorticoids regulate an inducibi

19 Kujubu D A, Herschman H R. Dexamethasone inhibits mitogen induction of the TIS 10 prostaglandin synthase/cyclooxygenase gene. $f$ Biol Chem of the TIS10 prostag

20 Lemmel E M. A placebo controlled double blind clinical trial of $7.5 \mathrm{mg}$ and $15 \mathrm{mg}$ of meloxicam in short term treatment of patients with rheumatoid arthritis (RA): Eur $\mathcal{F}$ Clin Pharmacol 1994; 47: A105(A 52). 